\title{
Interdisciplinarity Works Best Across Institutions
}

The International Conference on "Interdisciplinarity Revisited: Materials Research as a Case Study" was held August 30-31, 1999 at The Pennsylvania State University. The conference was organized and chaired by Rustum Roy, founding Director in 1962 of Penn State's Materials Research Laboratory, who had also organized the first international interdisciplinary materials science and policy meeting in 1969, also held at Penn State. He was assisted by his colleagues: L. Eric Cross, Evan Pugh Professor Emeritus of Electrical Engineering; Robert E. Newnham, ALCOA Professor Emeritus of Solid State Science; and Della M. Roy, Professor Emerita of Materials Science.

In exploring the history, practice, and status of interactive research, the participants of the conference discussed collaborative work among researchers from different disciplines; ${ }^{*}$ from various types of institutions; and from different parts of the sequence of research activities, that is, from "knowledge" through application to the final product. This model was depicted as "I ${ }^{3} R$ " (Figure 1). Richard Brook, Chief Executive of Engineering and Physical Sciences Research Center in the United Kingdom, suggested the addition of a fourth element: international, that is, $I^{4} R$, recognizing the globalized nature of much current research.

$R$. Roy, in his opening address, used the famous quote from Ortega y Gassett ${ }^{\dagger}$ as he "preached" the case for interdisciplinarity. The conference focused on four angles: What historical and current driving forces are behind interdisciplinary materials research, what researchers have learned from experience, what forces help further this type of research, and what recommen-

\footnotetext{
* Participants not only crossed the physical science disciplines but also others, including social science and integrative medicine.

t"The need to create sound syntheses and systemizations of knowledge...will call out a kind of scientific genius which hitherto has existed only as an aberration: the genius for integration. Of necessity this means specialization, as all creative effort does, but this time, the [person] will be specializing in the construction of the whole The momentum which impels investigation to dissociate indefinitely into particular problems, the pulverization of research, makes necessary a compensative control-as in any healthy organization-which is to be furnished by a force pulling in the opposite direction, constraining centrifugal science into a wholesome organization...the selection of professors will depend not on their rank as investigators but on their talent for synthesis." -Jose Ortega y Gasset, "Mission of the University"
}

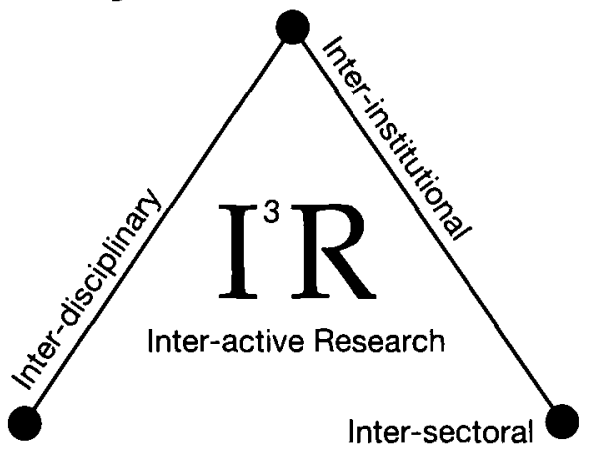

pline, various participants made the following recommendations for restructuring universities: Thus to encourage much more interaction among disciplines after tenure, tenured faculty with joint appointments should make up $25-50 \%$ of each department. Every department would then be free to choose in what areas it wants to interact, but yet be forced to encourage faculty to interact. Departments should be given incentives to carry out projects focused on societal needs thereby forming an interdisciplinary systems approach to solving societal problems.

Figure 1. The model shows the relationships of departments to interdisciplinary units described by R. Roy in 1977, which K. Mame (Assoc. V.P. for Graduate Studies and Research at the University of Dayton) referred to as the most comprehensive model yet presented.

dations can be made by the participants. After two days of presentations and discussions from university, industry, and government leaders, predominantly from the United States, but also from Canada, England, Germany, India, Japan, Russia, and Switzerland, participants of the conference, drawn mainly from materials but also from other fields, contributed recommendations for enhancing interdisciplinary research.

Major discussion developed around how to substitute other tried and true methods such as those used by the U.S. Department of Defense (DoD) for 50 years or strongly modify the peer-review system in order to promote interdisciplinary and innovative research. The predominant suggestion for pre-proposal to postresearch evaluation was to create a panel of mixed experts (representing depth of knowledge in various disciplines) with generalists (representing broad knowledge of various disciplines) in order to generate debate. They also suggested that the Weinberg Criteria be used in this connection. Alvin Weinberg, founding Director of Oak Ridge National Laboratory, in a seminal paper had suggested that reviewing peers should be drawn largely from neighboring fields, not only specialists in the topic being reviewed.

The participants acknowledged that the main barrier to the practice of interdisciplinary research came not so much from the funding agencies as from the higher educational university system itself. While agreeing that perhaps junior faculty members could concentrate on developing their expertise and reputation in a single disci-
Simple opportunities to mingle and network across departmental lines could be facilitated with faculty clubs or simple events such as coffee breaks. Debate ensued whether research at the universities should be knowledge-driven, enabling faculty, students, and postdoctorates to concentrate on exploring and understanding in their own specialties; or societal needs-driven, enabling them to solicit funds from relevant government agencies; or market-driven, enabling immediate funding for research from companies with student preparation for industrial work; or venture-driven, using university revenue derived from patent royalties.

Mark Myers, Executive Vice President of Xerox; Alastair Glass, Head of Photonics Research Laboratory of Bell Labs, Lucent Technologies; Steward Flaschen, Former

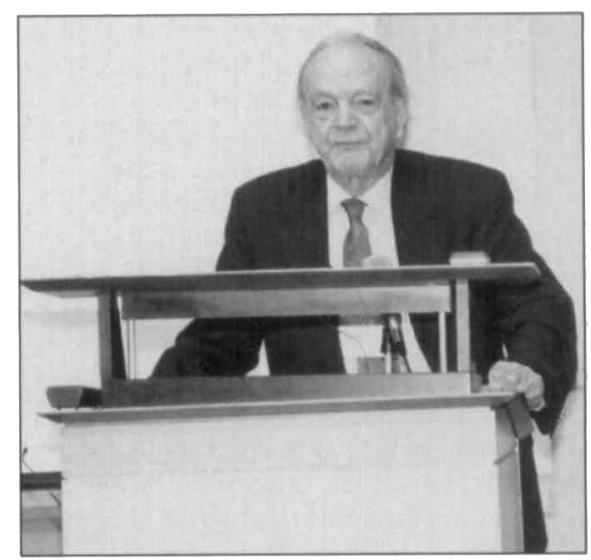

Harry C. Gatos (Massachusetts Institute of Technology) delivered a message from Arthur von Hippel who founded the interdisciplinary Laboratory of Insulation Research at MIT in the 1940s and also is the namesake of MRS's top award, "I realized early in my career that the ground for new technical advances was most fertile at the boundaries of the classical disciplines of science and engineering." 


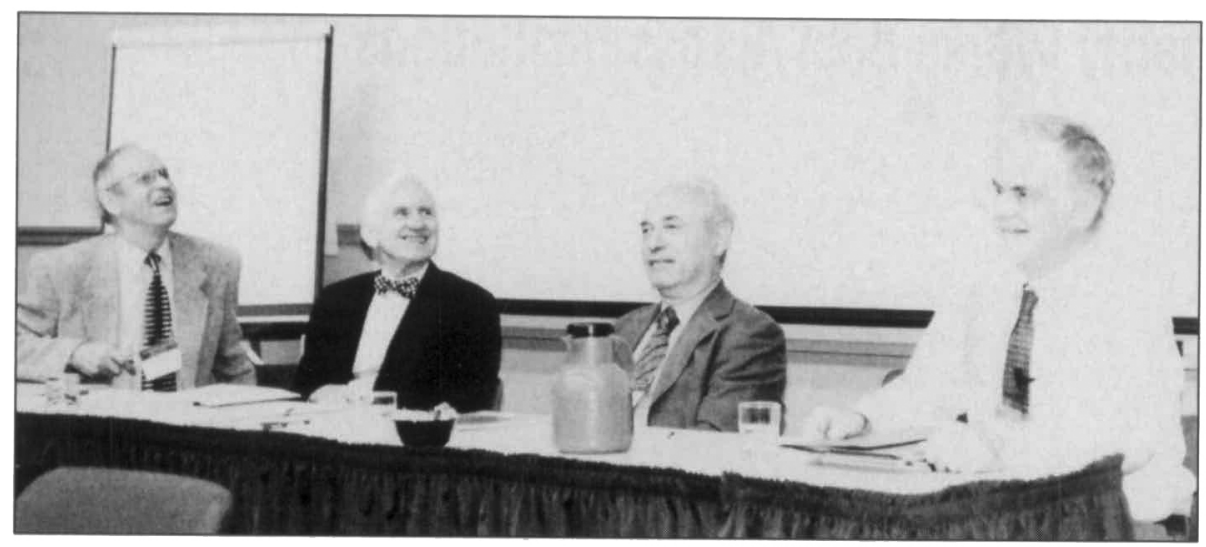

During a panel presentation on Interdisciplinarity in Universities: Teaching and Public Service, Yuri Tretyakov of Moscow State Lomonossov University (left) described the development of the interdisciplinary degree program in materials research in Russia. In 1990, the study of materials technology was housed in technical universities, separated from the study of basic science and humanities which was taught in the classical universities. However, in 1997, technical universities included courses on humanities, and the classical Moscow State University incorporated materials science. Lack of funding to support innovative programs, though, remains a problem. Merton C. Flemings of Massachusetts Institute of Technology (2nd from the left) described a very large, collaborative research and education program between MIT and two universities in Singapore. He attributed the possibility of these collaborations to advances made in information technology. The other panelists shown are (left to right) Eric Baer (Case Westem Reserve University) and Robert Cahn (University of Cambridge).

Executive Vice President for Research for ITT; and Kathy Taylor, Head of Physical Chemistry at GM, conveyed from their contemporary industrial experience how interdisciplinary, or $I^{3} R$ in general, is absolutely mandated and ubiquitous in industry. As some put it, "One is amazed that the universities have taken so long to 'get it."' There is no high-tech materials research which is not interactive anymore. Tracy Gaudet, M.D., Executive Director of the Program in Integrative Medicine at the University of Arizona, gave a lucid and widely appreciated description of a very new field of innovation in interdisciplinary academic education-and the obstacles encountered.

The question of intellectual property, specifically in the United States, generated the most vigorous discussion. Several industrial participants commented that it is easier for industries to work with their competitors than with universities because competitors will negotiate patent licensing while universities want to own the patent and, according to industry, set unrealistic barriers to its exploitation. On one side of the debate, industry says that some students even use the company's facilities and resources to conduct research, then later sell the rights to a competitor. On the university side, when industry owns the patents they ask students and faculty to postpone publication of their dissertations and articles for the sake of protecting proprietary information. The majority view of the participants, however, was that the university should remove itself from the intellectual property realm, or re-think its positions based on current reality checks.

Participants also discussed and agreed upon how the infrastructure of universities should be reformulated to facilitate interdisciplinary collaborations. Jane Alexander, Deputy Director of Defense Advanced Research Projects Agency (DARPA) in Washington, DC, suggested that universities provide the space, that is, laboratories and offices in the same center, in which researchers from the various disciplines may work together. By working physically in the same environment, she said, scientists of different disciplines can realize each other's capabilities and challenges as they pursue world issues such as space exploration. Arden L. Bement, Jr., Distinguished Professor of Engineering and Head of the School of Nuclear Engineering at Purdue University, recognized that these research centers would need to be transferred from the domain of the Materials Research and Engineering Department into established primary centers independent of any one discipline or subdiscipline. For example, Rodney Erickson, Provost of The Pennsylvania State University, described plans to transform a subdisciplinary building into a Life Sciences Building that will house researchers in the various biological and physical sciences.

Along with changing the infrastructure, Bement advocates a shift in the academic value system. He said that academicians function in a "win-lose" paradigm in which researchers "are conditioned to think they can win only if someone else loses." Bement advocates an evolution in materials research at the academic realm from a win-lose to a win-win paradigm. In a "win-win" environment, creativity in interdisciplinary research would be enhanced by synergy among multiple investigators. Interdisciplinary synergy would require trust, respect, and empathy among the researchers as they take a more collaborative approach to cutting-edge research projects. The researchers would share scientific and technological resources as they span the range from basic concepts to applied technologies.

George Bugliarello, Chancellor of Polytechnic University of New York, longtime champion of the cause and former President of the National Association of Science, Technology, and Society, an interdisciplinary field in U.S. higher education, gave a thorough intellectual analysis in his capstone speech on "The Interdisciplinarity Imperative." His talk was complemented by the detailed empirical studies reported by Katy Marre, Associate V.P. at the University of Dayton, and Mohammad Karim, Chair of $\mathrm{EE}$ at the University of Tennessee, showing data on the problems university faculty encounter in interdisciplinary work.

In keeping with the mission of "spreading the word," Proceedings of the conference will be published as a book and will be made available on the Web. Because the Proceedings will be distributed to major funding agencies and foundations, the texts will include recommendations on procedures that participants believe can catalyze or facilitate any aspect of interactive research.

See the MRS website (www.mrs.org) for additional coverage of the conference, including the role of professional societies and journals; a message from Frederick Seitz, Former President of the National Academy of Sciences and 1993 MRS Von Hippel Award recipient; a view of interdisciplinarity in the case study of integrative medicine; and the official conference report by the Chair, R. Roy.

For a list of upcoming conferences, see Calendar on page 85. 
